\title{
Translation and cross-cultural adaptation of a Nepali version of the Dutch Participation and Activity Inventory for Children and Youth (PAI - CY) with visual impairment
}

Srijana Adhikari ${ }^{1 *}$ (D) Ellen Bernadette Maria Elsman ${ }^{2}$, Ruth Marie Antoinette van Nispen ${ }^{2}$, Fleur van Rens ${ }^{3}$, Radhika Upreti Oli ${ }^{1}$, Suman S. Thapa ${ }^{1}$ and Gerardus Hermanus Maria Bartholomeus van Rens ${ }^{2}$

\begin{abstract}
Background: Visual impairment is an important cause of disability in children. There is a lack of information on rehabilitation needs and low vision support services for children with visual impairment in Nepal. This is a pilot study designed to translate, culturally adapt and pre-test the Dutch version of the Participation and Activity Inventory for Children and Youth (PAI-CY) with visual impairment aged 7-17 years to develop a Nepali version. Questionnaires (PAI-CY versions for 7-12 and 13-17 years) were translated using standardized methods and were culturally adapted by a panel of experts. They were pretested to evaluate comprehensibility and relevance among six children with visual impairment and blindness. Finally, participants completed a questionnaire evaluation form.

Results: The translation and cultural adaptation process resulted in the adaptation of nine items to make them suitable for Nepali culture. Most children had comprehensibility problems with some specific items because of vocabulary, sentence structure and the composition of items. Most of the children were satisfied with the questionnaires.

Conclusion: The study resulted in the development of a Nepali version of the PAI-CY. We worked with a small group of content experts and a small but representative sample of children which allowed us to use rigorous translation procedures to address language and cultural differences. A population based study has been planned to investigate the psychometric properties of these questionnaires.
\end{abstract}

Keywords: Nepal, Children, Visual impairment, Blindness, Participation and activity

\section{Background}

Childhood blindness is an important cause of disability in children [1]. It has been listed as one of the priority diseases by the World Health Organization (WHO) [2]. The prevalence and etiology of childhood blindness differs between countries and regions [3-6]. It has been estimated that of the 1.4 million blind children, two thirds live in low income countries in Asia and Africa [7].

\footnotetext{
* Correspondence: srij_a@yahoo.com

${ }^{1}$ Tilganga Institute of Ophthalmology, PO Box 561, Gaushala, Kathmandu, Nepal

Full list of author information is available at the end of the article
}

Children in low income countries mostly suffer from diseases which are either preventable or treatable. During the past few decades, causes of childhood blindness in developing countries have slowly shifted from malnutrition and infectious diseases such as vitamin A deficiency and congenital rubella syndrome to uncorrected refractive errors, congenital cataracts, retinopathy of prematurity and cerebral visual impairment. In high income countries, albinism, optic nerve diseases, cerebral visual impairment and hereditary retinal dystrophies dominate the list of causes of childhood blindness [8-10]. Although there is no national registry, there is a handful of 
data available on visual impairment and blindness among children in Nepal. An epidemiological study conducted in three ecological regions in Nepal has shown that the prevalence of childhood blindness and visual impairment among children 0 to 14 years of age is $0.067 \%$ and $0.10 \%$, respectively [11]. Moreover it was shown that about $80 \%$ of children suffer from avoidable blindness with uncorrected refractive error being the leading cause. Between 2008 and 2011, a nationwide survey among 778 children from 67 integrated schools for the blind was performed in different parts of Nepal. Corneal diseases due to vitamin A deficiency followed by retinal and lens disorders were the most common causes of blindness and visual impairment in these children [12]. Finally, a disability registry in Nepal has shown that there are around 3000 children who attend special schools for children with visual impairment [13]. According to the United Nations Convention on the Rights of People with Disabilities, disabled individuals, irrespective of the extent of their disabilities have the right to participate fully within society and in community life [14]. Children are in their formative stage approximately until the age of 18 years. Limitations caused by a visual disability, but also the lack of proper low vision services and guidance might prevent children from participating in age appropriate activities. This may ultimately have a negative impact on their development and psychosocial wellbeing [15-18]. For example Kef S found that of adolescents with visual impairment had fewer friends and smaller personal networks compared to their sighted counterparts. These factors are known to be an important component of functional social development. These visually impaired adolescents had fewer friends than their sighted counterparts. However, Huurrte $\mathrm{T}$ et al. found that the psychosocial developmental outcomes of many adolescents with visual impairment was similar to the psychosocial development of their sighted peers. Yet some adolescents with visual impairment, girls in particular, required more support in their psychosocial development.

There are no designated low vision services or support services in Nepal for children with visual impairment. Until now no study has addressed the issue of the lack of these services in terms of children's developmental needs, participation in activities or quality of life. Therefore, it is not clear if children with visual impairment in Nepal have specific needs which would enable them to participate more fully.

A well-designed measurement tool to identify participation needs in children with visual impairment is important for any country or community. Participation could be measured using patient-reported outcome measures (PROMs). Many PROMs for measuring participation and activity limitations in adults with visual impairment exist $[19,20]$, and some are available for children with disability in general [21]. The field of PROMs for pediatric populations with visual impairment is more novel. In recent years, several PROMs for children with visual impairment have been developed [22, 23], but they are not yet available in the Nepali language. Instead of developing a new PROM to measure the participation and activity limitations of children in Nepal, it is considered to be more efficient to translate and culturally adapt an existing PROM, which is known to possess good psychometric properties.

The Participation and Activity Inventory for Children and Youth (PAI-CY) is one of those PROMs, and was originally developed in a Dutch pediatric population [24-29]. The PAI-CY was designed to measure the participation needs of children with visual impairment. Important advantages of the PAI-CY are that it consists of various age versions, covering the entire age range from 0 to 18 years, and that from age 7 years and onwards selfreport forms are available alongside proxy-report forms for caregivers. Its psychometric properties are extensively evaluated using modern measurement techniques.

Translation and adaptation of existing tools to a local language is practiced worldwide. However, a good translation approach should follow proper guidelines of translation, adaptation and pretesting procedures [30, 31]. The objective of this study is to translate the Dutch PAICY questionnaires for children aged 7-12 years and 1317 years, to adapt items to make them relevant to the Nepali context, and pretest the questionnaires to determine its feasibility.

\section{Methods}

The study was first approved by the local Institutional Review Committee which was then forwarded to and approved by the Nepal Health Research Council. The study adheres to the tenets of declaration of Helsinki. Written informed consent was provided by parents of participating children, whereas assent was provided by the children themselves.

\section{Instruments}

The Dutch PAI-CY questionnaires were developed for four age groups which reflected the developmental age bands of the WHO; 0-2 years (proxy-report), 3-6 years (proxy-report), 7-12 (proxy and self-report) and 13-17 years (proxy and self-report) [25-28]. This study concerns the PAI-CY 7-12 and 13-17. The PAI-CY 7-12 consists of 54 items which cover nine domains of contextual meaning: play, social contact, mobility, leisure time, communication, school, self-reliance, acceptance/ self-consciousness and finance. The PAI-CY 13-17 years consists of 55 items which cover eight domains, namely: leisure time, mobility, social contact, communication, 
school, self-reliance, acceptance, /self-consciousness and finance. The domains provide contextual meaning to respondents. The items have a four-point Likert-type scale: (1) not difficult; (2) slightly difficult; (3) very difficult and (4) impossible. Furthermore, if an item is not relevant for the child, the response not applicable can be selected, which is treated as a missing value. Each domain also entails one open ended section "explanation or comments" which gives children the freedom to report any other relevant issues.

\section{Translation}

The translation process was carried out in two steps. First, questionnaires were translated from Dutch to English to create an English version. Second, the English version was translated to Nepali to create a final Nepali version.

Figure 1 shows the translation process.

\section{Translation from Dutch to English}

Forward translation Forward translation from Dutch to English was conducted by two translators. The first was a native Dutch speaker with advance mastery in English language. The translator had vast experience with measurement of PROMs and was involved in the development of the Dutch PAI-CY and related validation studies $[23,24]$. The second is Dutch but residing in English speaking countries (UK, Australia) for many years and can be considered bilingual. She has been involved in the development of questionnaires and is an expert in the field of mobility and activity One English version was created by combining the two translations, along with a written report. This was finalized after review by the investigators of this study and reaching consensus by the two translators.

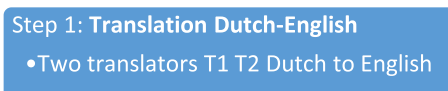

Step 2: Synthesis English version

Synthesized T1 and T2 into T12

Step 3: Back Translation English-Dutch

The synthesised T12 back translated to Dutch BT1 and BT2

Step 4: Translation English-Nepali

Two translators T1N and T2N English to Nepali

Step 5: Synthesis Nepali version

Synthesized T1N and T2N into T12N

Step 6: Back Translation Nepali-English

Synthesized T12N back translated into English BT1N and BT2N

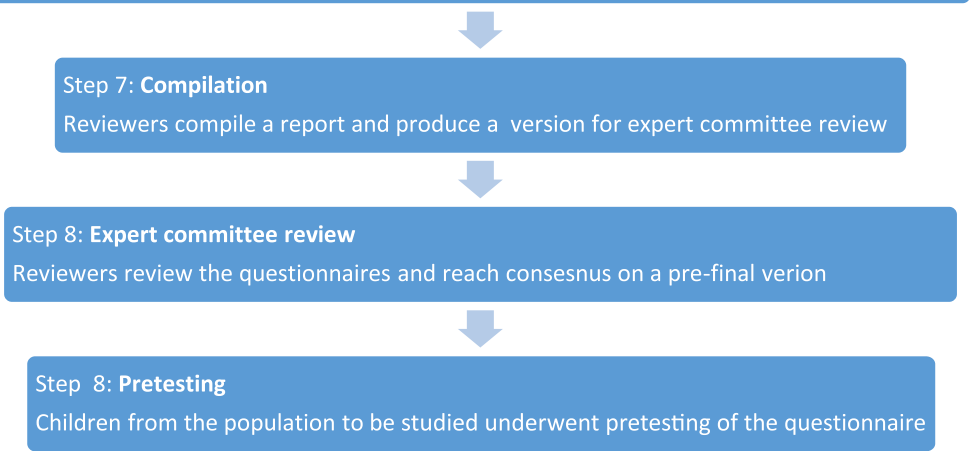

Fig. 1 Translation and Pretesting 
Backward translation Backward translation from English to Dutch was conducted by two native Dutch speakers with advanced mastery of the English language. Both of them are university faculty members and are involved in various validation studies They were blinded to the original versions of the translated questionnaires. The back translations of both translators were then reviewed by the investigators and the two translators. The translated versions well matched the original Dutch questionnaires and no major discrepancies were found.

The study supervisor, who was fluent in both Dutch and English, and the translators convened on several occasions to develop a single English version for each questionnaire. This was done to eliminate any discrepancies in translation and to ensure expressions and concept equivalence. This generated the first reconciled English version of each questionnaire. The final English versions were then created after review and reaching consensus by the investigators and four translators. They were checked by a native English speaker from Australia.

\section{Translation from English to Nepali}

Forward translation The final English version was forward translated into Nepali by two independent translators, both were ophthalmologists and had good mastery of English and Nepali. Both the translators were native Nepali speakers with advanced mastery of English language. They are involved in ophthalmology practice for the last 5 years. Both the translations were combined into final written report after review and reaching consensus by the investigators and the translators.

Backward translation The backward translation was conducted by the two independent translators who were native Nepali speakers. One was an ophthalmologist working in the field for the last 5 years and the other was a public health expert with experience in eye research for the last 3 years. The backward translation did not show any major discrepancies from the original English versions of the questionnaires.

The final Nepali version were created after discussion between researchers, the public health experts and ophthalmologists. The Nepali version was further reviewed by the investigators to ensure that the questions had the intended meaning in the Nepali language.

\section{Cultural adaptation}

The Dutch and Nepali researchers reviewed the final questionnaires together in a group discussion. It was checked whether items which represent Dutch life styles should be changed to items that better reflected the Nepali context. Four words in the items which represent Dutch life styles were changed to items that better reflected the Nepali context. The words "cycling", "skateboard", "kickscooter"," preparing sandwitch" were changed to "walking", "skipping","running" "Preparing bread and jam" respectively.

\section{Pretesting}

After the translation and cultural adaptation process, a pretest of the Nepali version of the PAI-CY was conducted to check the comprehensibility and relevance of the questions. The pretesting was conducted using interview. The interviews were carried out by principal investigator of the study who is an ophthalmologist. Children with hearing impairment or cognitive abnormalities were excluded from the study Children with visual impairment and blindness according to WHO criteria were included in the study. Demographic information, visual acuity, and causes of blindness and visual impairment were collected using WHO prevention of blindness (PBL) form [32]. Blindness was defined as the best corrected visual acuity of less than $3 / 60$ in the better seeing eye. Low vision (Moderate and severe visual impairment) was defined as the best corrected visual acuity of less than $6 / 18$ but better than $3 / 60$ in better seeing eye [33].

Item specific comprehensibility problems resulting from terminology, complex question structure, unclear formulation of questions, problems in understanding the response categories, and instructions were noted. Further pretesting helped to identify relevance of questions in Nepali context. Six children from the outpatient department of the Tilganga Institute of Ophthalmology, three with low vision and three with blindness, were invited to pretest the questionnaires. The questions were asked in a quiet room by the investigator. The responses were immediately filled out using a paper-and-pencil format. The time required to complete the interview for each child was recorded. Children were accompanied by either their mother or father. If children did not understand the questions, they could ask for assistance from their parents. The procedure was similar for both blind and visually impaired children.

Upon completion of questionnaires in pretest, children were asked to evaluate the questionnaires. There were five evaluation questionnaires regarding a, satisfaction $b$, length $\mathrm{c}$, difficulty $\mathrm{d}$, lacking questions e, relation to daily activities. The responses were recorded on the evaluation form, response categories included (a) yes (b) a little (c) no. were used in the evaluation form. During analysis these responses were categorized as either positive $(+)$, neutral $( \pm)$ or negative $(-)$.

\section{Statistical analysis}

Descriptive statistics were calculated for the demographic data (i.e. age, sex, visual acuity and the cause of blindness and low vision). The satisfaction regarding the 
questionnaires was assessed as were data in the evaluation form. The data were entered and analyzed in Microsoft Excel and data analysis was performed.

\section{Results}

\section{Translation and cultural adaptation}

During the course of translation, four items were changed from the Dutch version of the PAI-CY to adapt the questionnaires to the Nepali culture. In the Mobility domain, the item "Cycling to school" was changed to going to school by "walking" in both PAI-CY versions. The games using "skateboard" and "kick scooter" were changed to "skipping" and "running". In the self- reliance domain "preparing a sandwich" was changed to "preparing bread and jam", which is popular in Nepal and more easily available than "a sandwich". From the group discussion with Dutch and Nepali researchers, the Dutch researchers who were the original developers of PAI-CY, mentioned that in the original validation study Dutch children stated missing various activities in the questionnaires $[27,28]$. These items were discussed for their relevance to the Nepali context. Following this discussion, 5 items were added in the PAI-CY 7-12 years (2 in "play", 2 in "mobility" and 1 in "school" domain while 6 items were added to PAI-CY 13 to 17 years (1 in "mobility", 1 in "school",1 in "communication", 1 in "“self-reliance" and 2 in "acceptance/ self-consciousness" domain). Table 1 shows the changes made in different domain categories of the questionnaires.

\section{Pretesting}

The six children who were enrolled in the study were between 7 and 17 years of age. The age of children, visual acuity, anatomical site of the primary ocular diagnosis and mean duration to fill in the questionnaires are presented in Table 2.

\section{Comprehensibility}

None of the participants had any major issues answering the questions. However, all children reported some difficulties in the interpretation of words or phrases in some items. In the "acceptance/ self-reliance" domain children had difficulty in interpreting the phrase "to accept that you cannot do certain things/activities," as "certain things" was deemed vague and non-specific. Hence it was advised to specify "certain things" like sports, or play music etc. This was applied to items in both age groups. In the age group 7-12 years, all three children required their parent's help to answer questions when they were unsure about the answer. In the "Communication" domain, children needed their parents help in three items: "tell your parents what you want to say, while they understand what you mean"” talk about feelings (for example: if you feel scared or sad or happy,) do you tell that to your parents" and "notice how other children are feeling". In the "Acceptance/Self-consciousness" domain children needed parents help with the item "empathize with others (for example: do you understand why a child in your class may sometimes be sad or upset)".

Table 1 Results of changes made after translation and cultural adaptation

\begin{tabular}{|c|c|c|}
\hline \multicolumn{3}{|l|}{ Age $7-12$ years } \\
\hline Domain & $\begin{array}{l}\text { Question } \\
\text { How difficult is it for you to: }\end{array}$ & $\begin{array}{l}\text { Added or changed } \\
\text { How difficult is it for you to: }\end{array}$ \\
\hline Play & & $\begin{array}{l}\text { Play on the ground? (Added) } \\
\text { Play indoor games like Ludo, block or doll games? (Added) }\end{array}$ \\
\hline Mobility & $\begin{array}{l}\text { Cycle independently (to school or a friend)? } \\
\text { Participate in high speed games (e.g. } \\
\text { kick biking, skating)? }\end{array}$ & $\begin{array}{l}\text { Walk to school or a friend's house? (Changed) } \\
\text { Participate in high speed games (e.g. skipping, running)? } \\
\text { (Changed) } \\
\text { Cross road with traffic at night? (Added) } \\
\text { Find your way in unknown environment? (Added) }\end{array}$ \\
\hline School & & Finish your homework independently? (Added) \\
\hline Self- reliance & Make a sandwich? & Make a jam and bread? (Changed) \\
\hline \multicolumn{3}{|l|}{ Age 13-17 years } \\
\hline Mobility & Cycle independently (to school or a friend)? & $\begin{array}{l}\text { Walk to school or a friend's house? (Changed) } \\
\text { Cross road with traffic at night? (Added) }\end{array}$ \\
\hline School & & $\begin{array}{l}\text { Take part in outside school activities like inter-school sports } \\
\text { competitions? (Added) }\end{array}$ \\
\hline Communication & & Recognize other people? (Added) \\
\hline Acceptance/self- consciousness & & $\begin{array}{l}\text { Do your activities without getting fatigued? (Added) } \\
\text { Divide your energy during the day? } \\
\text { (Added) }\end{array}$ \\
\hline Self- reliance & & Pay attention to your facial care? (Added) \\
\hline
\end{tabular}


Table 2 Characteristics of participants

\begin{tabular}{lll}
\hline & $\mathbf{7 - 1 2}$ years $(\boldsymbol{n}=\mathbf{3})$ & $\mathbf{1 3 - 1 7}$ years $(\boldsymbol{n}=\mathbf{3})$ \\
\hline Mean Age in years & 8.6 & 15.6 \\
Visual acuity & 1 & 2 \\
$\quad$ Blind & 2 & 1 \\
$\quad$ Low vision & & 1 \\
Ophthalmic diagnosis & & \\
$\quad$ Retina & 2 & 1 \\
$\quad$ Optic Nerve & 1 & 1 \\
$\quad$ Lens & & \\
$\quad$ Cornea & & $35.0(20-45)$ \\
Duration in minutes & & \\
$\quad$ Mean (Range) & $33.3(25-45)$ &
\end{tabular}

One child suggested adding an open-ended question to the item related to music. In the age group 13-17 years all children had difficulties in interpreting the question on "handle or dealing with feelings of love" in the "social contact" domain. Therefore, this item was changed to "express the feeling of love". A summary of the pretesting results is described in Table 3.

Based on the analysis of the evaluation form, it seemed that most children were satisfied with the questionnaires Table 4 describes the results of the evaluation form. However, the response was "neutral to negative" regarding the length of the questionnaires.

\section{Discussion}

In our study, we translated two sets of PAI-CY questionnaires for two different age groups, 7-12 years and 1317 years. The PAI-CY was translated from Dutch to English and from English to Nepali. A two-step translation process had to be followed because of a lack of experts who were able to translate directly from Dutch to Nepali and vice versa and were also knowledgeable with respect to the construct and population. Some cultural adaptation of items was required to enhance the applicability of the questionnaire within the Nepali context. For example, cycling is a very common form of transportation for children in the Dutch society. However, in Nepal it is sometimes used by children as recreational activity, but only few children use cycling as mode of transportation to go to school or other places. Also a few items which were not present in the Dutch PAI-CY were added to the Nepali version to better represent the live experiences of children with visual impairment in Nepal. These items were added based upon suggestions made by the Dutch children after extensive validation of questionnaires and after Dutch and Nepali researchers affirmed their applicability to the Nepali culture. Hence by common consensus and in collaboration with Dutch developers these items were added in the questionnaires. The Dutch developers recommended to include these items but not to include them in the scoring until validity and reliability is demonstrated. We are planning to study the reliability and validity of these tools including the added items in larger population of children.

Pretesting is a method of checking that the tool performs as intended and is understood by those individuals who are supposed to respond to it [34, 35], .Pretesting was performed in blind and visually impaired children to check the comprehensibility and reliability of questionnaires. During the process, there were minor issues encountered which have been changed accordingly. However, one major comprehensibility issue we encountered was that younger children were not able to answer

Table 3 Results of pretest in terms of comprehensibility

\begin{tabular}{|c|c|c|c|}
\hline Subcategory & Description of problem & Domain/ Item no & Possible solution \\
\hline $\begin{array}{l}\text { Problem with } \\
\text { instruction }\end{array}$ & $\begin{array}{l}\text { Younger children had difficulty } \\
\text { to answer questions and took } \\
\text { mother's help }\end{array}$ & $\begin{array}{l}\text { Communication/ 1,3,9 } \\
\text { Item } 1 \text { "How difficult is if for you to tell your parents what } \\
\text { you want to say; while they understand what you mean" } \\
\text { Item } \mathbf{3} \text { :How difficult is it for you to talk about feelings (for } \\
\text { example: if you feel scared or sad or happy,) do you tell } \\
\text { that to your parents"; } \\
\text { Item } \mathbf{9}^{\prime \prime} \text { How difficult is it for you to notice how other } \\
\text { children are feeling } \\
\text { Acceptance/ } 4 \\
\text { How difficult is it for you to empathize with others (for } \\
\text { example: do you understand why a child in your class may } \\
\text { sometimes be sad or upset)"? }\end{array}$ & $\begin{array}{l}\text { Younger children can answer questions } \\
\text { with the help of caregiver }\end{array}$ \\
\hline
\end{tabular}

$\begin{array}{ll}\text { Item specific } & \text { The question was too vague. } \\ \text { problem } & \text { How difficult is it for you to } \\ & \text { accept that you can't do } \\ & \text { "certain things" }\end{array}$

Acceptance Self-reliance/ 3

you can't do

Item specific How difficult for you to handle Social contact / 7 problem or deal with feeling of love
"Certain things" to be specified like read, play etc. The question was modified to

"How difficult it is for you to accept that you can't do certain things, for example read, play etc."

The question was modified to: How difficult it is it for you to "express feeling of love" 
Table 4 Results of Evaluation of questionnaires by children and young adults (All questions)

\begin{tabular}{|c|c|c|c|}
\hline \multirow[t]{4}{*}{$\begin{array}{l}\text { How did you like this interview/ how satisfied are you with the } \\
\text { interview }\end{array}$} & Rating & $\begin{array}{l}\text { No of } \\
\text { children }\end{array}$ & $\begin{array}{l}\text { Only one child found the process tiring and expressed } \\
\text { some dislike }\end{array}$ \\
\hline & + & 5 & \\
\hline & \pm & 1 & \\
\hline & - & 0 & \\
\hline \multirow[t]{3}{*}{ Did you find this interview lengthy? } & + & 1 & Most of the children found the questionnaire too long \\
\hline & \pm & 1 & \\
\hline & - & 4 & \\
\hline \multirow[t]{3}{*}{ Was it difficult to answer questions? } & + & 0 & All children found the questions a little difficult \\
\hline & \pm & 6 & \\
\hline & - & 0 & \\
\hline \multirow[t]{3}{*}{ Any questions you want to add? } & + & 0 & No one wanted to add any questions \\
\hline & \pm & 0 & \\
\hline & - & 6 & \\
\hline \multirow[t]{3}{*}{ How do the questions relate to your daily activities ${ }^{a}$} & + & 3 & \\
\hline & \pm & & \\
\hline & - & & \\
\hline
\end{tabular}

${ }^{\mathrm{a}}$ Asked to children aged 13-17 years

items in some domains independently. They needed their parents help to answer those questions. Maybe these age groups in Nepal are less expressive or not confident enough to answer those questions. Therefore, it is important for children in this age group to have an adult present during completion of the questionnaires to ensure accurate responses.

The evaluation showed that most of the children were satisfied with the questions, which is similar to the pilot study conducted in Dutch children [23]. However, the length of the questionnaires was deemed an issue as most children indicated the administration took too long. This problem of endurance may be overcome by providing training to the personnel taking the interview and applying measures to keep children interested during the interview as well as providing a break if needed.

Our pilot study addresses a gap in the literature with regards to the lack of scientifically valid measurement tools to identify rehabilitation needs in blind and visually impaired children in Nepal. Although the LV Prasad Eye Institute in India has developed and validated a questionnaire which is probably more tailored towards the Nepali context, it measures the construct of functional vision, which is related to participation but does not assess children's participation needs [36]. The development of measurement instruments or questionnaires is a research process that includes a number of carefully planned stages. Culturally adapting measurement tools from one cultural group to another can be a challenging task [37]. It should follow certain standard guidelines [38] (http://www.who.int/substance_abuse/research_ tools/translation/en/). We were able to work with a small group of content experts and with a small but representative sample. This allowed us to use rigorous translation procedures to address language and cultural differences which is often overlooked in studies using translated questionnaires [39, 40]. A larger populationbased study has been planned to further develop and validate the Nepalese PAY-CY questionnaires, by studying their psychometric properties as a quantitative instrument to assess the participation needs of Nepali children with visual impairment or blindness. Furthermore, this pilot study provided us with valuable experiences for selecting and recruiting participants and administering the PAI-CY questionnaires.

\section{Conclusion}

This pilot study is an initial, but an important step in the validation of questionnaires in Nepalese children. Although there were some minor comprehensibility and response category problems, the questionnaires were considered to include items that reflect the most important activities and participation aspects of children with visual impairment. Most of the items and response categories were clear to the users. The adaptations made to the questionnaires after pretesting are likely to improve satisfaction with the content, the clarification of questions, and satisfaction with the questionnaires with regard to compiling a rehabilitation plan.

\section{Abbreviations}

PAI-CY: Participatory and Activity Inventory Children and Youth; WHO: World Health Organization; PROM: Patient Reported Outcome Measure 


\section{Acknowledgements}

We would like to acknowledge VU University Medical Centre Amsterdam, for the study and funding support.

\section{Authors' contributions}

SA: Carried out the research as principal investigator. Wrote manuscript. EE: Contributed in the study design and methodology. Contributed in manuscript writing and editing. FR: Contributed in the study design and methodology. Contributed in manuscript writing and editing. VN: Contributed in study design and methodology. Contributed in manuscript writing and editing. RO: Contributed in translation and cultural adaptation process. ST: Supervised the study. GR: Supervised the study. Contributed in manuscript editing. The author(s) read and approved the final manuscript.

\section{Funding}

The study is the part of PhD thesis from VU University Amsterdam The funding was available for the translation of questionnaires. However, no funding was available for design of study, collection, analysis and interpretation of data and writing the manuscript.

\section{Availability of data and materials}

The datasets used and/or analyzed during the current study are available from the corresponding author on reasonable request.

\section{Declarations}

\section{Ethics approval and consent to participate}

The study was first approved by the Institutional Review Committee of the Tilganga Institute of Ophthalmology which was then forwarded to and approved by the Nepal Health Research Council. The study adheres to the declaration of Helsinki. Written informed consent was provided by parents of participating children, whereas ascent was provided by the children themselves.

\section{Consent for publication}

Not applicable.

\section{Competing interests}

The authors declare that they have no competing interest.

\section{Author details}

${ }^{1}$ Tilganga Institute of Ophthalmology, PO Box 561, Gaushala, Kathmandu, Nepal. ${ }^{2}$ Department of Ophthalmology, VU University Medical Centre and the Amsterdam Public Health Research Institute, PO Box 7057, 1007 MB Amsterdam, The Netherlands. ${ }^{3}$ Murdoch University, Perth, Australia.

Received: 9 December 2020 Accepted: 13 July 2021

Published online: 25 August 2021

\section{References}

1. Rahi, J. S., Gilbert, C. E., Foster, A., \& Minassian, D. (1999). Measuring the burden of childhood blindness. The British Journal of Ophthalmology, 83(4), 387-388. https://doi.org/10.1136/bjo.83.4.387 PMID: 10434856; PMCID: PMC1723010.

2. World Health Organization (1999). Blindness and Deafness Unit \& International Agency for the Prevention of Blindness. Preventing blindness in children: report of a WHO/IAPB scientific meeting, Hyderabad, India. World Health Organization.

3. Kemmanu, V., Hegde, K., Giliyar, S. K., Shetty, B. K., Kumaramanickavel, G., \& McCarty, C. A. (2016). Prevalence of childhood blindness and ocular morbidity in a rural pediatric population in southern India: The Pavagada pediatric eye disease Study-1. Ophthalmic Epidemiology, 23(3), 185-192. https://doi.org/10.3109/09286586.2015.1090003 Epub 2016 May 4. PMID: 27142419.

4. Teoh, L., Rahi, J., Solebo, A., et al. (2018). The British childhood visual impairment and blindness study (BCVIS2): 1-year outcomes. Archives of Disease in Childhood, 103, A5.

5. de Verdier, K., Ulla, E., Löfgren, S., \& Fernell, E. (2018). Children with blindness - Major causes, developmental outcomes and implications for habilitation and educational support: A two-decade, Swedish population-based study. Acta Ophthalmologica, 96(3), 295-300. https://doi.org/10.1111/aos.13631.
6. Awan, A., Jamshed, J., Khan, M., \& Latif, Z. (2018). Prevalence and causes of visual impairment and blindness among school children in Muzaffarabad, Pakistan. International Journal of Scientific Reports, 4(4), 93-98. https://doi. org/10.18203/issn.2454-2156.IntJSciRep20181393.

7. Rahi, J., \& Gilbert, C. (2016). Epidemiology and world-wide impact of visual impairment in children. In S. R. Lambert, \& C. Lyons (Eds.), Taylor and Hoyt's pediatric ophthalmology and strabismus, (5th ed., ). Elsevier.

8. Gilbert, C., Bowman, R., \& Malik, A. N. (2017). The epidemiology of blindness in children: changing priorities. Community Eye Health, 30(100), 74-77 PMID: 29483749; PMCID: PMC5820629.

9. Solebo, A. L., Teoh, L., \& Rahi, J. (2017). Epidemiology of blindness in children. Archives of Disease in Childhood, 102(9), 853-857. https://doi.org/1 0.1136/archdischild-2016-310532 Epub 2017 May 2. Erratum in: Arch Dis Child. 2017 Oct;102(10):995. PMID: 28465303.

10. Boonstra, N., Limburg, H., Tijmes, N., van Genderen, M., Schuil, J., \& van Nispen, R. (2012). Changes in causes of low vision between 1988 and 2009 in a Dutch population of children. Acta Ophthalmologica, 90(3), 277-286. https://doi.org/10.1111/j.1755-3768.2011.02205.x Epub 2011 Aug 4. PMID: 21812942

11. Adhikari, S., Shrestha, M. K., Adhikari, K., Maharjan, N., \& Shrestha, U. D. (2015). Causes of visual impairment and blindness in children in three ecological regions of Nepal: Nepal Pediatric Ocular Diseases Study. Clinical Ophthalmology, 9, 1543-1547. https://doi.org/10.2147/OPTH.S89431 PMID: 26347452; PMCID: PMC4556258.

12. Shrestha, J. B., Gnyawali, S., \& Upadhyay, M. P. (2012). Causes of blindness and visual impairment among students in integrated schools for the blind in Nepal. Ophthalmic Epidemiology, 19(6), 401-406. https://doi.org/10.3109/ 09286586.2012.722245 PMID: 23171210

13. National Policy and Plan of Action on Disability (2006) Government of Nepal, Ministry of Women, Children and Social Welfare, Kathmandu.

14. UN General Assembly, Convention on the Rights of Persons with Disabilities, 13 December 2006, A/RES/61/106, Annex I. Available at: https://www. refworld.org/docid/4680cd212.html. Accessed 4 Aug 2021.

15. Huurre, T., \& Aro, H. (1998). Psychosocial development among adolescents with visual impairment. European Child \& Adolescent Psychiatry, 7(2), 73-78. https://doi.org/10.1007/s007870050050

16. Kef, S. (2002). Psychosocial adjustment and the meaning of social support for visually impaired adolescents. Journal of Visual Impairment \& Blindness, 96(1), 22-37. https://doi.org/10.1177/0145482X0209600104.

17. Stewart, D. (2006). Evidence to support a positive transition into adulthood for youth with disabilities. Physical \& Occupational Therapy in Pediatrics, 26(4), 1-4. 17135066. https://doi.org/10.1080/J006v26n04_01.

18. Day, S. (1997). Normal and abnormal visual development. In D. Taylor (Ed.), Paediatric ophthalmology, (2nd ed., pp. 13-28). Blackwell Science.

19. Denniston, A. K., Kyte, D., Calvert, M., \& Burr, J. M. (2014). An introduction to patient-reported outcome measures in ophthalmic research. Eye (London, England), 28(6), 637-645. https://doi.org/10.1038/eye.2014.41 Epub 2014 Mar 14. PMID: 24625379; PMCID: PMC4058607.

20. Finger, R. P., Tellis, B., Crewe, J., Keeffe, J. E., Ayton, L. N., \& Guymer, R. H. (2014). Developing the impact of vision impairment-very low vision (IVI-VLV) questionnaire as part of the LoVADA protocol. Investigative Ophthalmology \& Visual Science, 55(10), 6150-6158. 25190656. https://doi.org/10.1167/ iovs.14-14731.

21. Rainey, L., van Nispen, R., van der Zee, C., \& van Rens, G. (2014). Measurement properties of questionnaires assessing participation in children and adolescents with a disability: A systematic review. Quality of Life Research, 23(10), 2793-2808. https://doi.org/10.1007/s11136-014-0743-3 Epub 2014 Jun 27. PMID: 24970678.

22. Tadic, V., Hogan, A., Sobti, N., Knowles, R. L., \& Rahi, J. S. (2013). Patient-reported outcome measures (PROMs) in paediatric ophthalmology: A systematic review. The British Journal of Ophthalmology, 97(11), 1369-1381. https://doi.org/10.113 6/bjophthalmol-2013-303350 Epub 2013 Jun 6. PMID: 23743433.

23. Hatt, S. R., Leske, D. A., Castañeda, Y. S., Wernimont, S. M., Liebermann, L., Cheng-Patel, C. S., ... Holmes, J. M. (2019). Development of pediatric eye questionnaires for children with eye conditions. American Journal of Ophthalmology, 200, 201-217. https://doi.org/10.1016/j.ajo.2019.01.001 Epub 2019 Jan 14. PMID: 30653960; PMCID: PMC6730562.

24. Elsman, E. B., Nispen, R. M., \& van Rens, G. H. M. B. (2017). Feasibility of the participation and activity inventory for children and youth (PAI-CY) and young adults (PAI-YA) with a visual impairment: A pilot study. Health and Quality of Life Outcomes, 15(1), 98. https://doi.org/10.1186/s12955-017-0677. 
25. Rainey, L., Elsman, E. B. M., van Nispen, R. M. A., van Leeuwen, L. M., \& van Rens, G. H. M. B. (2016). Comprehending the impact of low vision on the lives of children and adolescents: A qualitative approach. Quality of Life Research, 25(10), 2633-2643. https://doi.org/10.1007/s11136-016-1292-8.

26. Elsman, E. B., van Nispen, R. M., \& van Rens, G. H. (2020). Psychometric evaluation of the participation and activity inventory for children and youth (PAl-CY) 0-2 years with visual impairment. Quality of Life Research, 29(3), 775-781. https://doi.org/10.1007/s11136-019-02343-1.

27. Elsman, E. B., van Nispen, R. M., \& van Rens, G. H. (2019). Psychometric evaluation of a new proxy-instrument to assess participation in children aged 3-6 years with visual impairment: PAI-CY 3-6. Ophthalmic and Physiological Optics, 39(5), 378-391. https://doi.org/10.1111/opo.12642.

28. Elsman, E. B., Peeters, C. F., van Nispen, R. M., \& van Rens, G. H. (2020). Network analysis of the participation and activity inventory for children and youth (PAI-CY) 7-12 years with visual impairment. Translational Vision Science \& Technology, 9(6), 19-19. https://doi.org/10.1167/tvst.9.6.19.

29. Elsman, E. B., van Nispen, R. M., \& van Rens, G. H. (2020). First stage psychometric testing of a new instrument for adolescents with visual impairment: The participation and activity inventory for children and youth (PAl-CY) 13-17 years. Journal of Patient-Reported Outcomes, 4(1), 1-10.

30. Beaton, D. E., Bombardier, C., Guillemin, F., \& Ferraz, M. B. (2000). Guidelines for the process of cross-cultural adaptation of self-report measures. Spine (Phila Pa 1976), 25(24), 3186-3191. https://doi.org/10.1097/00007632-2 00012150-00014 PMID: 11124735

31. Terwee, C. B., Prinsen, C. A. C., Chiarotto, A., Westerman, M. J., Patrick, D. L., Alonso, J., ... Mokkink, L. B. (2018). COSMIN methodology for evaluating the content validity of patient-reported outcome measures: a Delphi study. Quality of Life Research, 27(5), 1159-1170. https://doi.org/10.1007/s11136-01 8-1829-0 Epub 2018 Mar 17. PMID: 29550964; PMCID: PMC5891557.

32. Gilbert, C., Foster, A., Négrel, A. D., \& Thylefors, B. (1993). Childhood blindness: a new form for recording causes of visual loss in children. Bulletin of the World Health Organization, 71(5), 485-489 PMID: 8261552; PMCID: PMC2393473.

33. World Health Organization (WHO). (2020). ICD-11 Reference guide 2019. https://icd.who.int/icd1 1 refguide/en/index.html.

34. De Vet, H., Terwee, C., Mokkink, L., \& Knol, D. (2011). Measurement in medicine: A practical guide (practical guides to biostatistics and epidemiology). Cambridge University Press. New York. https://doi.org/10.1017/CBO9780511 996214.

35. Collins, D. (2003). Pretesting survey instruments: An overview of cognitive methods. Quality of Life Research, 12(3), 229-238. 12769135. https://doi.org/1 0.1023/a:1023254226592

36. Gothwal, V. K., Lovie-Kitchin, J. E., \& Nutheti, R. (2003). The development of the LV Prasad-functional vision questionnaire: A measure of functional vision performance of visually impaired children. Investigative Ophthalmology \& Visual Science, 44(9), 4131-4139. 12939337. https://doi. org/10.1167/iovs.02-1238.

37. Elsman, E. B. M., Tadić, V., Peeters, C. F. W., van Rens, G. H. M. B., Rahi, J. S., \& van Nispen, R. M. A. (2019). Cross-cultural validation of the Functional Vision Questionnaire for Children and Young People (FVQ_CYP) with visual impairment in the Dutch population: challenges and opportunities. BMC Medical Research Methodology, 19(1), 221. https://doi.org/10.1186/s12874-01 9-0875-9 PMID: 31795950; PMCID: PMC6889469.

38. Acquadro, C., Conway, K., Hareendran, A., \& Aaronson, N. (2008). European regulatory issues and quality of life assessment (ERIQA) group. Literature review of methods to translate health-related quality of life questionnaires for use in multinational clinical trials. Value in Health, 11(3), 509-521. https:// doi.org/10.1111/j.1524-4733.2007.00292x Epub 2007 Dec 18. PMID: 18179659.

39. Auchter, J. E., \& Stansfield, C. (1997). Linking tests across languages: Focus on the translation and adaptation process. Annual Meeting of the National Council on Measurement in Education. (ERIC Document Reproduction Service No. ED411263).

40. Kim, A., \& Lim, E. Y. (1999). How critical is back translation in cross-cultural adaptation of attitude measurement?. Annual Meeting of the American Educational Research Association. (ERIC Document Reproduction Service No. ED430014).

\section{Publisher's Note}

Springer Nature remains neutral with regard to jurisdictional claims in published maps and institutional affiliations.

\section{Submit your manuscript to a SpringerOpen ${ }^{\circ}$ journal and benefit from:}

- Convenient online submission

- Rigorous peer review

- Open access: articles freely available online

- High visibility within the field

- Retaining the copyright to your article

Submit your next manuscript at $\boldsymbol{\nabla}$ springeropen.com 